\title{
Representation and Deconstruction of Gender Constructs in David Levithan's Every Day (2012)
}

\author{
$1^{\text {st }}$ Almasafira Nurarafah \\ English Studies Program, Faculty of \\ Humanities, Universitas Indonesia \\ Depok, Indonesia \\ almasafira.nurarafah@ui.ac.id
}

\author{
$2^{\text {nd }}$ Adriana Rahajeng Mintarsih* \\ Literature Department, Faculty of \\ Humanities, Universitas Indonesia \\ Depok, Indonesia \\ rahajeng@ui.ac.id
}

\begin{abstract}
David Levithan is renowned as an author who does not portray stereotypical LGBTQ characters in his novels. His 2012 novel, Every Day, presents one such gender nonconforming protagonist. The novel's plot revolves around a genderless and unembodied spirit who travels from one body to another every day. This study intends to investigate gender constructions articulated in Every Day. The textual analysis accomplished during this research endeavor suggests that Every Day problematizes the representation of gender and challenges traditional gender constructions through its characters.
\end{abstract}

Keywords-Every Day, David Levithan, gender construction, gender non-conforming

\section{Introduction}

David Levithan is renowned as a writer of young adult fiction that features LGBTQ characters. Most narratives typecast gender [3] and characters who do not conform to normative binary gender identities do not usually get happy endings [2]. David Levithan's novels are very different. He does not portray LGBTQ characters through any stereotypes. His novel Every Day (2012) [1], for example, is categorized as LGBTQ fiction because the protagonist is gender nonconforming. Named just "A," the main character of this novel is a genderless and disembodied soul who is compelled to jump from one body to another every day and just for a day. Since A does not want to claim any particular gender, the pronoun which is used to address $\mathrm{A}$ is the gender-neutral pronoun "they." Throughout the novel, A occupies the bodies of men, women, and non-binary/gender non-conforming people without the knowledge of the body in which they will wake up the next morning and that they will inhabit for a day. Moreover, A does not consider gender or biological sex to matter fundamentally in a relationship. Rather, having occupied countless bodies since birth, A can appreciate the personalities that lie beyond the physical appearances of people. A tries to challenge social constructs of gender while inhabiting the bodies of other people.

Abate [3], Malcom and Sheahan [4], and Reuling [2] have discussed how certain narratives can challenge gender constructs that prevail in our societies by portraying nonconforming characters who transcend stereotypical gender constructions. The gender binary still operates as the mainstream in most societies around the world. Hence, most people cannot escape the inclination to conform to the binary construction of gender [2]. The perception of gender identity is still often equated with the biological sex of a person [3], [2] and transgender individuals are expected to modify all their previous gender identification indicators to the new biology that is to be adopted [5]. However, such binary assumptions fail to appreciate that all transgender individuals do not desire demarcation within the traditional male-female gender system [5]. Similarly, it is difficult for genderqueer individuals to choose to be a man or a woman [2]. Several literary studies have attempted to scrutinize narratives with genderqueer characters [6], [7], [8]. However, no scholar has yet examined Every Day's (2012) [1] genderqueer protagonist, A. This study, therefore, seeks to contribute to the extant academic discourse on non-binary gender constructions by analyzing the manner in which this novel critiques the tight conceptualization of gender by societies through the description of these constructions and through A's opposition to those constructions. In so doing, this paper attempts to elucidate how the narrative representation of a genderqueer character can be empowering instead of stereotypical.

\section{Method}

This research endeavor uses qualitative textual analysis as its methodology since David Levithan's novel Every Day (2012) [1] forms the primary data source of this study. The data obtained from this text are analyzed using Laura Palazzani's Gender in Philosophy and Law [9]. Some other previous critiques are also cited in the discussion section to bolster the analysis presented in this paper. The examined data include the novel's characters, plot, point of view, and theme. This study scrutinizes the novel from two viewpoints: first, it evaluates the novel's portrayal of gender constructions in its characters except for the protagonist, A; second, the paper attempts to illuminate how A deconstructs gender constructs while "embodying" other characters.

\section{Results and Discussion}

Every Day (2012) [1] delves into difficult issues of social gender construction. A is genderless and disembodied. However, A is also forced to wake up every morning within another body that A can only occupy for a day. While in the body of others, A discusses the social conceptualization of gender by experiencing how gender constructions shape the lives of ordinary young people who must inhabit the same body for their entire lives. One way or another, the social imposition of narrow gender constructs obliges people to conform and those who do not adhere to the prescribed constructions must deal with the social consequences of nonconformity. The representation of gender can be understood through the established power relations between men and women, the cultural construction of beauty, and also the mainstream perception of the LGBTQ community.

Waking up first in Justin's body, A realizes Justin's relationship with Rhiannon, his girlfriend for more than a year. 
A says, "Justin is the one who makes the first move. Justin is the one who figures things out. Justin is the one who says what they're going to do" (p. 9) [1]. Justin is the one in control, and Rhiannon usually only tags along because she is afraid that she will make Justin mad if she asserts her views. She asks Justin whether he is mad at her when A is Justin's body. She states, "Are you mad at me?" (p. 5) and "I'm glad you're not mad at me," or "I just want everything to be okay" (p. 6) [1]. It is thus clear that Justin and Rhiannon's relationship conforms to the patriarchal construction of a genderappropriate heterosexual relationship. Palazzani [9] clarifies that the patriarchal conceptualization of females as subordinate to males can also make women subjugate their self-esteem to the "superior" male gender. Thus, Justin plays the dominant role in the relationship, while Rhiannon performs the submissive function of following in his footsteps and agreeing with him. It is also important to note Rhiannon's wariness around Justin. She is scared of making him mad at her for no reason. In real terms, it could be asserted that she is being subject to a form of psychological abuse by her boyfriend Justin and that this abuse affects her emotional wellbeing. Karakurt \& Silver [10] explain that the assertion of dominance and control over one's partner can be categorized as psychological abuse in a relationship.

The construction of men having a 'higher' position does not solely apply to relationships but also in other contexts. When A occupies the body of Mark, a basketball player, the coach calls out one of the players during a practice session for failing to score a shot: "When one of the teammates botches a shot, the coach tells him to stop being a girl" (Day 5931) [1]. Thus, when men fail to appropriately execute their tasks, in this case to shoot the ball into the hoop, they are compared to women, who are believed to be "weaker" than men. The phrase "being a girl" also implies "like a girl" and it indicates how society mocks men whose actions do not live up to mainstream gender expectations. According to Palazzani [9], patriarchal society is hierarchical and its human members occupy two positions: women are subordinate and men are dominant. This assertion is confirmed in the context of sports, which is a stereotypically male-dominated field, and where the hierarchy between men and women still clearly applies. Further, the coach's words also emphasize that athletic men still perceive women as "lower" than men and compare men who are physically "weak" to women.

The novel also discusses beauty standards to which people must conform to be "accepted" in society. In Ashley's body, A realizes the kinds of social privileges that good-looking people enjoy. A describes Ashley as a very good-looking person, "Then I look in the mirror. I am not pretty. I am not beautiful. I'm top-to-bottom gorgeous" (p. 148) [1]. A also compares Ashley's body to Beyoncé's. "I wake up the next morning in Beyoncé's body. Not the real Beyoncé. But a body remarkably like hers. All the curves in all the right places" ( $p$. 148) [1]. Therefore, not only is Ashley's face beautiful, but she also has a body that society would deem 'desirable'. Stereotypically, those adjudged to be beautiful by social standards have easier lives than those who do not measure to the mainstream standards of beauty. In certain situations, attractive men and women can use their good looks to their benefit [11].

In Ashley's case, attractiveness can also bring her disadvantages. In Ashley's body, A realizes that Rhiannon is more distant, not just because they are in a girl's body but also because this body is very attractive. "I want to hold her hand, but I sense it wouldn't work. I know she's not going to reach my hand, not unless I need it. This is the problem with being so beautiful-it can render you untouchable" (p. 151) [1]. Rhiannon seems to feel inferior to Ashley because of her beauty. Ashley is also objectified by others.

When she walks into the room, heads actually turn. Most of them are attached to men a good thirty years older than her. I'm sure she's used to it, but it freaks me out...He gives Rhiannon her hello, but he's gaping at me when he does" (p. 160, emphases have been added to the original) [1]

Frith et al. [12] argue that the female body is traditionally sexually objectified in most patriarchal societies. In Ashley's case, this focus on her physical appearance-her beautiful face and body - is very evident. The phrases "heads turn" and "gaping" exemplify her objectification. Society would have women believe that the action of men turning their heads to look at them is as a form of appreciation of their extraordinary beauty when it is actually a form of objectification. A's reaction, "freaks me out", also reveals their awareness of her objectification by others, especially male members of society.

On the other hand, those who do not conform to conventional beauty standards are marginalized. Finn is an overweight 16-year-old. A describes him as "Fat. Flabby, unwieldy fat" (p. 270) [1]. In Finn's body, A experiences the way Finn is seen because of his body. "And there are the looks I get - such undisguised disgust. Not just from other students. From teachers. From strangers. The judgment flows freely" (p. 271) [1]. Overweight people are usually "stigmatized and punished" by others [11]. One's physical appearance is always judged by society against its conformity to socially set standards of beauty, health, fitness, or general appearance. The appraisal becomes even more stringent when a person cannot be placed within the socially acceptable standard ranges that are imposed. DeJong claims that overweight people are to blame for their own conditions [11]. Finn is constantly judged because of his overweight body, and because he does not fall within the purview of the beauty construction. Society commonly views overweight bodies as disgusting because fat people are believed to neglect their bodies and to exercise no control over what and how much they eat.

The social construction of body image even influences A's own position and they become conflicted. A is not sure whether or not they should begin to rationalize the social expectations about overweight people. A, who usually does not criticize the body of the people that they inhabit, unconsciously starts to judge Finn's body. A also says that they are actually not like Finn. "The reason you're not seeing it is because he's so unlike me. You're not feeling it because I'm not like this" (p. 274) [1]. However, A is ultimately remorseful about judging Finn's body like other people.

I feel guilty about how relieved I am to be normal size the next morning. I feel guilty because I realize that while before I didn't care what other people thought, or how other people saw me, now I am conscious of it, now I am judging alongside them" (p. 276) [1] 
Thus, the social beauty construct is so powerful that it can influence even otherwise enlightened minds. A does not generally agree with mainstream views. However, they start to question their own standpoint. Hence, the immense influence wielded by gender and other social constructions is elucidated: even people like A who do not follow the norm can begin to question their own beliefs about certain phenomena.

This novel also tackles the issue of society's perception of the LGBTQ community. One apparent perception is attributed to Rhiannon, A's partner, who becomes especially apparent when A occupies female bodies. A becomes aware of Rhiannon's distinct reactions to them when they inhabit a female body. Rhiannon is less affectionate and tends to maintain physical distance from A, not once, but several times. "I remember Rhiannon's hesitation to kiss me longer when I was Kelsea (p. 142);" "She still keeps a physical space between us - there will be no leaning on shoulders or holding hands right now (p. 159);" and, "I notice she's less affectionate with me when I'm in a girl's body, but I don't call her on it" (p. 225) [1]. A realizes that Rhiannon's behavior toward them is different when they inhabit a girl's body. This differential response perhaps involves Rhiannon's own heterosexual female identity. Living in a society where the gender binary system is still dominant, it is difficult for her to alter her internalized perception of same-sex relationships. That a woman should be in a relationship with a man is a gender equation that has been passed down countless generations. Those who do not conform to the heterosexual norm may be socially judged and found wanting in most cultures. Heterosexual relationships are deemed compulsory in most societies, and people thus feel obliged to be heterosexual [9] whatever their natural state in the gender spectrum.

Rhiannon even states to A that she still perceives them as a male, even though A never claims themselves to be a man. She states, "I want you to know, if you were a guy I met-if you were the same guy...There might be girls out there who could deal with it" ([1] p.p. 279-280, emphases added to the original text). In Rhiannon's imagination, A remains "a guy I met." She even states, "There might be girls out there" when talking about A's relationship partners. A also notices how her attitude changes when they are in a man's body, indicating perhaps that Rhiannon only wants to show her affection for A when they inhabit the body of men. "I take her hand and she doesn't pull away. Is this because something between us has changed, or is it only because my body has changed? Is it easier for her to hold Adam Cassidy's hand?" (p.175) [1]. It is also very apparent that even though A's character does not subscribe to the binary, Rhiannon's perception of A remains bound to the gender binary system, symbolizing the enduring force of the dominant social system. Society still compels people, who may be innately LGBTQ in their orientations, to conform to the gender binary system. According to Palazzani [9], being inside the gender binary scheme and having a heterosexual relationship are still considered natural in most societies.

Communities sometimes also tend to be ignorant toward the LGBTQ community whether in terms of gender identity or sexuality. Once again, Rhiannon exemplifies this ignorance. Rhiannon's ignorance about Vic's gender identity is apparent when A occupies the body of Vic, a trans man.
"My name's Vic. I'm a biological female, but my gender is male." Rhiannon sighs. "I don't even know what that means." I start to explain, but she cuts me off." (p. 257); "There's such resignation in her voice, but I can't tell what she's actually resigned herself to. "So you're a girl who's a boy?" she says. "Something like that." I sense she doesn't want to get into it" (p. 258) [1]. Rhiannon's ignorance of Vic's gender reflects mainstream society's lack of understanding of sex and gender. Societies often confuse the terms sex and gender, believing biological sex and gender construction to be identical terms that can be interchangeably used [9]. Palazzani [9] states that traditionally, one's biological sex is the only factor determining one's gender. Since Vic's biological sex is female, people around him see him as female. "Whereas Vic's parents couldn't help seeing who he used to be, and so many friends and strangers couldn't help seeing who he didn't want to be anymore" (p. 256) [1]. The general ignorance about Vic's transgender identity once again highlights the fact that the gender binary system remains the dominant social system and that those who do not conform to this structure are forced to fit into a superimposed binary classification.

Besides critically scrutinizing representations of gender construction, Every Day (2012) [1] also problematizes other constructs created by societies. A refuses to subscribe to imposed gender constructs from the very first chapter when they wake up in Justin's body. The real Justin is the controlling male in his relationship with Rhiannon. However, A opposes this equation in the one day they spend in Justin. A appreciates Rhiannon, lets her take the lead, and shows her a more caring side. Unlike Justin, A seeks her opinion: "Let's go somewhere," I say. "Where do you want to go?" (p. 9). Rhiannon does not respond because deciding where they should go is usually Justin's decision and not hers. A persists and asks her again "Where do you want to go?" (p. 10) [1]. A also does not do the things that Justin does, such as subjecting her to emotional abuse. Instead, unlike Justin, A takes Rhiannon's feelings and opinions into account. "Are you okay?" I ask. I see the surprise on her face, even as she tries to cover it. This is not something that Justin normally asks" (p. 4); "I know this is dangerous. Justin is not good to her" (p. 12); "If I were really Justin, I would find something wrong with her. Right now. Tell her. Yell. Bring her down. Put her in place. But I can't. I'm not Justin" (p. 13) [1]. Even when they occupy a male body, A cannot conform to established social expectations from men. Palazzani [9] explains the social construction of communal and agentic roles. Communal roles may be characterized by terms such as submissive, cooperative, caring, and are thus associated with women. On the other hand, agentic roles are identified as aggressive, competitive, dominant, and are naturally associated with men. It thus becomes clear that A does not conform to the stereotypical male roles. Men are not socially constructed to demonstrate care or acknowledge the opinions of. Atypically, A also does not act aggressively toward Rhiannon as Justin does. Therefore, when A occupies Justin's body, the relationship between Justin and Rhiannon becomes more equal; neither takes a dominant or submissive position.

A also challenges gender construction while inhabiting the body of other teenagers. In Marc's body, A cries in public. The exhibition of emotions is usually considered to be a womanly trait. Men are usually deemed tough and assertive and are thus less likely to bare their feelings in public. However, A does 
not hesitate to cry in public even when they occupy a male body, once again challenging the mainstream construction. A also does not take into consideration phenomena that are traditionally associated with particular genders. A demonstrates their intelligence and interest in science, math, history, and even literature. In Justin's body, A purposely inscribes quotations from Shakespeare, Kerouac, and Dickinson's in Justin's notebook. A can also discuss the laws of thermodynamics or the life of Thomas Jefferson in flawless English while in Valeria's body. A, being genderless and free of a body of their own, is able to deconstruct the conception that the domain of science belongs to men while literature is for women. In their very characterization, A represents a challenge to the rigid construction, making it seem natural that it is possible for a person to integrally own both masculine and feminine traits. Palazzani [9] claims that since gender constructions are indeed created by people, they can also be changed and deconstructed.

Besides gender, as mentioned above, A also poses a challenge to prevailing conceptions of beauty and body image. In Ashley's body, A discusses the construction of beauty standards. While in her body, A tries not to do the things that she always does to maintain her beauty. A says "A lot of work has gone into this face, this body. I'm sure there's complete morning regiments that I'm supposed to undergo before heading into the day. I don't want to have any part of it, though" ([1], p.p. 148-149). The beauty construct expects women to always present themselves in an attractive way. The achievement of a good outward appearance is one of the most important aspects of the gender stereotype imposed on women [11]. To achieve the requisite attractiveness, women must undergo and perform certain actions to conform to the prevailing beauty standard. However, A is not interested in perpetuating this construct and purposefully avoids the performance of the actions expected of Ashley. A intentionally does not follow Ashley's daily beauty routine because of their belief that her looks are not all that matter about her.

The image of the ideal woman is consistently associated with thinness [13] in certain societies. Similarly, the ideal man has a "muscular and trim body" [11]. Thus, women and men undergo trials and tribulations to achieve that ideal body, for example by dieting or exercising. Even though exercising usually is more associated with men, in real life exercising is done by both genders. A wakes up one morning in the body of an extremely popular girl named Vanessa. She must accomplish her workout routine every single day. "She runs at least two miles every morning, and I am already late for the routine. She has to make do with a single mile, and I can almost hear her chiding me for it" (p. 211) [1]. However, while A occupies her body, they do not want to follow the punishing schedule. Mishkind et al. [11] argue that Western society has placed a body image burden on people, who must engage in health-promoting activities by undergoing life-style changes and applying rigorous self-management to achieve the ideal body.

A also explains Vanessa's stringent rules about appropriate dressing. A projects Vanessa's ideas about appearance by imagining what she would say if she was still in her own body. Imagining Vanessa's words and voice, A says,
Is that a backpack that Lauren has on? I guess she's acting like she's in third grade until her chest fills in. And oh my God, why is Felicity wearing those socks? Are those kittens? I thought only convicted child molesters were allowed to wear those. And Kendall's top? I don't think there's anything sadder than an unsexy trying to dress sexy" (p. 211) [1].

The popular Vanessa is thus likely to judge people according to the manner in which they present themselves. A does not want to judge others in the same way, as can be corroborated by A's expressed beliefs about attractiveness. Mishkind et al. [11] state that appearance has traditionally been one of women's biggest concerns. A wants to change such views by not taking the appearance of people and even the body that they are in seriously.

This body image construct is also challenged by $\mathrm{A}$ in Hamilton's body. Even though A is forced to work out, A tries to not follow Hamilton's usual routine. "I don't feel I have a choice. Even though part of the body desperately wants more sleep, another part is awake, ready to go. It wants to be worked" (Day 5909) [1]. The body also forces A to eat more. "At lunch, I try to eat reasonably, but the body wants more. I feed it" (Day 5909) [1]. Hamilton's body requires more food because this body requires extra nutrition to obtain the desired muscle mass. McCreary and Sasse [13] argue, "The most desirable body shape for men emphasizes muscle mass and physical bulk, what researchers refer to as the muscular mesomorph" (p. 297). They also assert the correlation between "muscularity and masculinity": men must look muscular in order to be seen as masculine (p.p. 297-298). Therefore, it is possible that Hamilton works out because of the felt need to look masculine. The same reason may apply to why A is against that idea. A states implicitly that men do not have to associate masculinity with a muscular body. A even educates another person so that he can change his ideas about a muscular body. "Not tonight," I tell him. "Why not?" "Because," I say, choosing my words carefully, "it's okay to take a break. You can't push yourself too hard."... "You don't need to. All you need to know is there are all kinds of strong." (Day 5909) [1]. A tries to explain to Hamilton's brother that he does not need to have a muscular body and exercise constantly to be seen as strong. The need to look strong is once again correlated with masculinity. It is also evident that A does not want to conform to this construction. A contests the idea of masculinity associated with a muscular body.

Next, A confronts the gender binary system. A always perceives themselves as genderless. A says, "I didn't think of myself as a boy or a girl-I never have" (p. 155) [1]. Unlike Rhiannon who still perceives A as a guy, A does not want to claim themselves as a guy or girl. It can be seen that A, who can also be qualified as a queer, tries to defy the construction of the gender binary. Palazzani [9] argues that queer people normally have a different understanding regarding their sexuality or gender than those who belong inside the binary male or female dichotomy. She also claims those who identify themselves as queer refuse to abide by the existing binary social code. Therefore, A, as a queer, rejects the gender binary system and even transcends the binary, saying "There were days I felt like a girl and days I felt like a boy...I had yet to learn that when it came to gender, I was both and neither ( $p$. 254 , emphases added to the original text) [1]. The use of the phrase "both and neither" signifies the way queer people think 
about their gender. Palazzani [9] explains how queers usually use "neither/nor" or "either/or" to express their gender (p. 45). They can identify with both sexes, and they can also classify themselves as neither sex. Therefore, it is apparent that A confronts the social gender binary by deciding not to specify their gender within the binary structure.

Moreover, A poses a challenge to the binary arrangement in terms of their sexuality, never asserting whether they prefer to be in a relationship with men or women. "In my experience, desire is desire, love is love. I have never fallen in love with a gender. I have fallen for individuals" (p. 142) [1]. It is hence understood that A does not want to label their sexuality as heterosexual, homosexual, or to assign labels of any other kind to his romantic interests. They prefer not to label their sexuality because they do not see the need for any specific label. The narrative elucidates that $\mathrm{A}$ has been in relationships with both men and women. Even though A's relationship with Rhiannon is the focal love story, A also dated a boy named Brennan briefly before they met Rhiannon. A's flexibility in terms of relationship partners can also be equated with the queer conception of fluidity. Palazzani [9] explains the queer intention to break down the heterosexual construction of relationships. Queer people choose to be open and flexible in terms of their sexuality and perceive every sexual choice to be equal, no matter the individual preferences of people. Therefore, they do not really see the need to conform to a heterosexual relationship, despite what society expects them to do. The novel makes it apparent that A defies sexual constructs by not conforming to heteronormativity.

\section{Conclusions}

Every Day (2012) [1] delves deeply into the issues of gender construction by problematizing the representation of people who affirm the construction while also divulging how the main character deconstructs these structures. Always a disembodied soul, A is unbound from birth to any set gender construction. Therefore, A questions why people's actions are limited by their gender. A's unique position and point of view problematize the normative construction. Further, A also intentionally counters the accepted construction in the time spent in other people's bodies. A chooses to question the actions of other people and later decides to not follow other people's actions. The novel presents both sides, the conformity to gender constructions and the challenging of the socially created structures; nonetheless, it critically questions mainstream conceptualizations of gender and bodies. Although Every Day (2012) [1] belongs to the genre of fantasy, which is based on the imagination of phenomena that are unreal or do not exist in actual life, the narrative also serves as social critique. The novel criticizes and even mocks social norms that insist on compelling people to imposed gender constructions that value one way of life over another. The exposure of young people to novels such as this one is certainly beneficial. Narratives such as this one challenge the status quo and make young readers think for themselves so they become encouraged to problematize mainstream gender constructions. The present study has only investigated Every Day (2012) [1]. Future researchers could undertake the study of other fantasy novels with gender non-conforming characters for comparison to this novel.

\section{References}

[1] Levithan, David. (2012). Every day. Knopf Books for Young Readers.

[2] Reuling, Manon. (2018). Multiplicity and Movement: construction of genderqueer identities in Orlando, Middlesex and Symptoms of being Human. Master's Thesis. Utrecht University.

[3] Abate, Michelle Ann. (2008). Trans/Forming Girlhood: Transgenderism, the Tomboy Formula, and Gender Identity Disorder in Sharon Dennis Wyeth's Tomboy Trouble. The Lion and the Unicorn, 32(1), 40-60. DOI: 10.1353/uni.2008.0007

[4] Malcom, Nancy L., \& Sheahan, Nicole. (2018). From William's Doll to Jacob's New Dress: The Depiction of Gender Non-Conforming Boys in Children's Picture Books From 1972 to 2014. Journal of Homosexuality. DOI: 10.1080/00918369.2018.1484635

[5] Diamond, Lisa M., \& Butterworth, Molly. (2008). Questioning gender and sexual identity: Dynamic links over time. Sex roles, 59(5-6), 365376. DOI: 10.1007/s11199-008-9425-3

[6] Bittner, Robert. (2017). Theorizing trans readership: Examining ways of reading trans themed young adult literature (Doctoral dissertation, Arts \& Social Sciences: Department of Gender, Sexuality, and Women's Studies).

[7] Bittner, Robert. (2016). (Im) Possibility and (in) visibility: Arguing against 'just happens to be' in Young Adult literature. Queer Studies in Media \& Popular Culture, 1(2), 199-214.

[8] Nadin, Joanna. (2016). Queen Bea: a novel [and] No me without you: how concepts of self as mutable and multiple shaped the YA novel Queen Bea (Doctoral dissertation, Bath Spa University).

[9] Palazzani, Laura. (2012). Gender in philosophy and law. Springer Science \& Business Media. DOI: 10.1007/978-94-007-4991-7_2

[10] Karakurt, Günnur., \& Silver, Kristin E. (2013). Emotional abuse in intimate relationships: The role of gender and age. Violence and victims, 28(5), 804-821.

[11] Mishkind, Marc E., Rodin, Judith., Silberstein, Lisa R., \& StriegelMoore, Ruth H. (1986). The embodiment of masculinity: Cultural, psychological, and behavioral dimensions. American Behavioural Scientist, 29(5), 545-562.

[12] Frith, Katherine., Shaw, Ping., \& Cheng, Hong. (2005). The construction of beauty: A cross-cultural analysis of women's magazine advertising. Journal of communication, 55(1), 56-70.

[13] McCreary, Donald R., \& Sasse, Doris K. (2000). An exploration of the drive for muscularity in adolescent boys and girls. Journal of American college health, 48(6), 297-304. DOI: 10.1080/07448480009596271 